\title{
Subliminal Diode Treatment of the Ciliary Bodies by Transscleral Cyclophotocoagulation with a 31.3\% Duty Cycle in the Treatment of Refractory Glaucoma: Safety and Efficacy

\author{
Zerin Hekalo, Karine Angioï, Etselle Neiter, Jean-Baptiste Conart and Toufic Maalouf
}

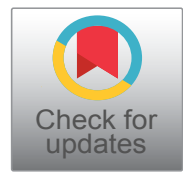

Department of Ophthalmology, CHRU-Nancy, France

*Corresponding author: Toufic Maalouf, Department of Ophthalmology, Nancy-Brabois University Hospital, Rue du Morvan, 54500 Vandoeuvre les Nancy, France, Tel: +3-33-83-15-30-29, Fax: +3-33-83-15-51-09

\begin{abstract}
Purpose: Micropulse Transscleral diode laser cyclophotocoagulation (MP-TSCPC) is an established method of treatment for refractory glaucoma. This study evaluates the efficacy in terms of reduction in intraocular pressure and/or treatment amount, and safety and side effects of the ciliary bodies using a subthreshold laser with a duty cycle of $31.3 \%$ with Supra $810 \mathrm{~nm}$ Subliminal Quantel Medical, at one year in patients with refractory glaucoma.
\end{abstract}

Methods: A retrospective, observational, single-center study conducted between January 2019 and November 2019 at Nancy University Hospital, includes 22 eyes. The inclusion criteria was patients with refractory glaucoma, defined as glaucoma with no longer response to medical or surgical treatment and/or painful eye. The exclusion criteria was eye which received any other procedure in order to destroy or weaken the ciliary body. All patients were reviewed at one week, one month and one year in post-operative period. Aetiology of glaucoma, history of surgery, change in intraocular pressure (IOP), glaucoma medication, visual acuity, pain symptoms, assessment of ocular surface pathology, and complication rate were documented.

Results: The study included 22 patients: 9 patients were female and 13 patients were male, and the mean age was $71.4 \pm 15$ years. The pre-operative mean IOP was $37.5 \pm$ $8 \mathrm{mmHg}$ and $26.5 \pm 12 \mathrm{mmHg}$ after laser procedure. The mean IOP reduction was $44.8 \%$ at one week, $30.4 \%$ at one month and $29.3 \%$ at one year after treatment, which was statistically significant ( $P$ value $<0.05$, paired Student's t-test). $93.7 \%$ of patients had improvement in pain symptoms after MP-TSCPC. The assessment of the surface pathology showed improvement in Oxford score that fell from 1.3 to 1. The mean number of ocular antihypertensive medication used was 2.2 before treatment and decreased to 1.7 one year after treatment, which represent a reduction of $25.1 \%$ of treatment score. All patients had unchanged visual acuity post-operatively except two. No significant complications or anatomic modifications were found after subliminal cyclophotocoagulation.

Conclusion: Subliminal cyclophotocoagulation with 31.3 duty cycle is effective and safe procedure for reducing IOP and/or pain in cases of refractory glaucoma.

\section{Keywords}

Glaucoma/therapy, Intraocular pressure, Micropulse transcleral cyclophotocoagulation

\section{Introduction}

Glaucoma is a progressive optic neuropathy that can lead to vision loss if left untreated [1]. Treatment involves lowering intraocular pressure to delay disease progression [2], either through local medical treatment (eye drops), surgical treatment (filtering surgery) or physical means (lasers). A new subthreshold diode laser therapy involving the treatment of the ciliary bodies has been developed: An infrared laser $(810 \mathrm{~nm})$ that targets the ciliary processes to reduce aqueous humour secretion [3]. The objective of our study was to evaluate its efficacy in terms of reduction in intraocular pressure and/or number of eye drops applied, as well as to assess the safety and side effects of the subliminal diode treatment of the ciliary bodies with a subthreshold laser at one year in patients with refractory glaucoma.

Citation: Hekalo Z, Angioï K, Neiter E, Conart JB, Maalouf T (2021) Subliminal Diode Treatment of the Ciliary Bodies by Transscleral Cyclophotocoagulation with a 31.3\% Duty Cycle in the Treatment of Refractory Glaucoma: Safety and Efficacy. Int J Ophthalmol Clin Res 8:126. doi.org/10.23937/2378346X/1410126

Accepted: June 05, 2021: Published: June 07, 2021

Copyright: (c) 2021 Hekalo Z, et al. This is an open-access article distributed under the terms of the Creative Commons Attribution License, which permits unrestricted use, distribution, and reproduction in any medium, provided the original author and source are credited. 


\section{Patients, Materials and Methods}

This was a retrospective, observational, single-centre study conducted between January 2019 and November 2019 at Nancy University Hospital.

The inclusion criterion was the existence of refractory glaucoma. Refractory glaucoma is glaucoma that is painful and/or no longer responding to medical or surgical treatment. We excluded any patients who had previously received another procedure designed to destroy or weaken the ciliary processes.

The surgical procedure was performed by a single operator. The laser used in our department is the Vitra 810 SubCyclo laser (Quantel Medical, Cournon d'Auvergne, France).

The procedures were performed under sterile conditions in the operating room and the subjects were treated as outpatients. The laser was applied to $3 \mathrm{~mm}$ of the limbus without prior identification of the position of the ciliary processes by transscleral illumination. The laser power was set to $2 \mathrm{~W}$. The exposure time was 80 seconds per semi-circumference with a duty cycle of $31.3 \%$. The probe was held perpendicular to the limbus, maintaining contact with the sclera while sliding it par- allel to the limbus over the upper semi-circumference and then the lower, respecting the 3 and 9 o'clock meridians. The patient was asked not to modify their local pressure-lowering treatment during the immediate post-operative period. Topical steroid anti-inflammatory treatment was initiated post-operatively for 1 month. All patients were reviewed at one week, one month and one year.

We recorded each patient's age, sex, initial diagnosis, affected side, history of filtering surgery and treatments at the time of the procedure. At each visit we measured visual acuity, performed a slit lamp examination to look for signs of local inflammation and score the ocular surface condition based on the Oxford grading scale (Figure 1), and measured IOP using the Goldmann applanation tonometer. We also rated pain on a numeric scale (NS) from zero (no pain) to 10 (maximum pain), asking the patient to estimate pain before and after treatment. Pressure-lowering treatment (local and general) was also scored. In order to quantify the initial and final medical treatment, we assigned one point for a single eye drop and two points for a combination of eye drops. Similarly, one point was assigned if general treatment with oral acetazolamide was required.

PANEL

GRADE CRITERIA

A
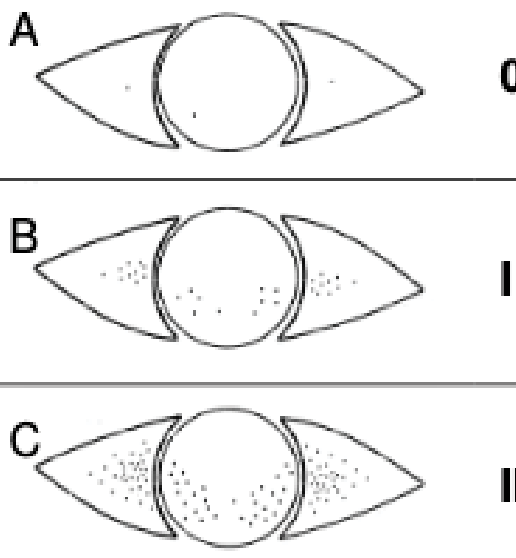

II

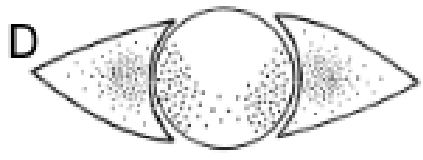

III

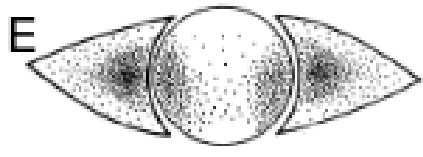

$>\mathrm{E}$

0
Equal to or less than panel $\mathrm{A}$

Equal to or less than panel B, greater than $A$

Equal to or less than panel $\mathrm{C}$, greater than $B$

Equal to or less than panel D, greater than $\mathrm{C}$

Equal to or less than panel $\mathrm{E}$, greater than $D$

Greater than panel E

Figure 1: Oxford grading scale for assessing the ocular surface condition. 




Figure 2: Change in intraocular pressure at 12 months for our 22 treated eyes.

Table 1: General characteristics of the patients studied.

\begin{tabular}{|l|l|l|l|l|l|l|l|}
\hline $\begin{array}{l}\text { Age } \\
\text { (years) }\end{array}$ & Sex & Side & $\begin{array}{l}\text { Type of } \\
\text { anaesthesia }\end{array}$ & Lens status & $\begin{array}{l}\text { History of } \\
\text { filtering surgery }\end{array}$ & $\begin{array}{l}\text { Pre- } \\
\text { operative } \\
\text { IOP (mmHg) }\end{array}$ & $\begin{array}{l}\text { Pre- } \\
\text { operative } \\
\text { pain (NS) }\end{array}$ \\
\hline & M 13 (59.1\%) & $\begin{array}{l}\text { Right 10 } \\
(45.4 \%)\end{array}$ & GA 11 (50\%) & $\begin{array}{l}\text { Pseudophakic 15 } \\
(68.2 \%)\end{array}$ & $\begin{array}{l}\text { Filtering surgery } \\
15(68.2 \%)\end{array}$ & 35.1 \\
\hline & F 9 (40.9\%) & $\begin{array}{l}\text { Left 12 } \\
(54.6 \%)\end{array}$ & PBA 11 (50\%) & Phakic 7 (31.8\%) & Naive 7 (31.8\%) & 36.6 \\
\hline $71.9 \pm 15$ & & & & & & $37.5 \pm 8$ & 3.1 \\
\hline
\end{tabular}

IOP: Intraocular pressure; NS: Numeric pain scale (0-10); GA: General anaesthesia; PBA: Peribulbar anaesthesia.

The study criteria were analysed:

- Pre-operative and post-operative IOP at 12 months regardless of cause and then according to aetiology (paired Student's t-test with significant results for $p<0.05)$.

- The difference between the number of pressure-lowering treatments before and after the operation (paired Student's t-test with significant results for $p<0.05)$.

The laser treatment was considered to be effective if the pain resolved and/or IOP was less than or equal to $21 \mathrm{mmHg}$.

\section{Results}

\section{Pre-operative results}

Nine women (40.9\%) and 13 men (59.1\%) were included between January 2019 and November 2019: A total of 22 subthreshold cyclodiode laser procedures for refractory glaucoma. The average age was $71.4 \pm$ 15 years, with a range of 40 to 89 years. Two patients required a second treatment procedure. There were a total of 10 right eyes (45.4\%) and 12 left eyes (54.6\%). The procedure was performed under general anaesthesia for 11 eyes (50\%) and under local or regional (peribulbar) anaesthesia for the other 11 (50\%). The characteristics of our population are summarised in Table 1.

Initial diagnosis: The initial diagnosis comprised: 8 cases of primary open-angle glaucoma (POAG) resis-
Table 2: Distribution of refractory glaucoma aetiologies in the study population.

\begin{tabular}{|l|l|}
\hline POAG & 8 \\
\hline NVG & 7 \\
\hline IG & 3 \\
\hline CG & 2 \\
\hline IOHT SOT & 1 \\
\hline MG & 1 \\
\hline
\end{tabular}

POAG: Primary open-angle glaucoma; NVG: Neovascular glaucoma; IG: Inflammatory glaucoma; CG: Congenital glaucoma; IOHT SOT: Intraocular hypertension with silicone oil retinal tamponade; MG: Malignant glaucoma.

tant to maximum eye drop treatment (36.4\%), 7 cases of neovascular glaucoma (NVG, 31.8\%), 3 cases of inflammatory glaucoma (IG, granulomatous panuveitis, $4.5 \%), 2$ cases of congenital glaucoma (CG, 9.1\%), 1 case of intraocular hypertension glaucoma secondary to silicone oil retinal tamponade (IOHT SOT, 4.5\%) and 1 case of malignant glaucoma (MG, 4.5\%) (Table 2).

Surgical history: Fifteen eyes (68.2\%) had undergone filtering surgery (14 trabeculectomies and 1 non-penetrating sclerectomy). Seven patients had received no prior filtering surgery. Fifteen patients $(68.2 \%)$ were pseudophakic and seven patients $(31.8 \%)$ were phakic with early to severe cataracts.

Intraocular pressure: The pre-operative mean IOP was $37.5 \pm 8 \mathrm{mmHg}$, with a range of $22 \mathrm{mmHg}$ to $58 \mathrm{mmHg}$ (Figure 2). The following mean IOPs were 
found: $35.7 \mathrm{mmHg}$ in the primary open-angle glaucoma group, $36.7 \mathrm{mmHg}$ for neovascular glaucoma, $28 \mathrm{mmHg}$ for inflammatory glaucoma, $37 \mathrm{mmHg}$ for congenital glaucoma, $26 \mathrm{mmHg}$ for hypertension caused by retinal detachment with silicone oil retinal tamponade, and $50 \mathrm{mmHg}$ for malignant glaucoma (Table 3).

Pain: Pain was present in 16 patients, with an average of 3.1 on a numeric pain scale (range 0-10) (Table 4).

Biomicroscopic examination: Inflammation of the ocular surface related to glaucoma medications was assessed by the Oxford score (Figure 1). The average score for the population was 1.3.

Initial treatment: Pre-operatively, the distribution of the number of eye drops was as follows: 1 eye (4.5\%) with monotherapy, 2 eyes (9.1\%) with dual therapy, 8 eyes $(36.4 \%)$ with triple therapy and 11 eyes $(50 \%)$ with quadruple therapy. Seven patients $(27.8 \%)$ were also receiving general treatment with oral acetazolamide (Diamox) (Table 5).

Table 3: Distribution of mean IOP values by aetiology.

\begin{tabular}{|l|l|l|}
\hline Aetiology & Number $(\mathbf{n})$ & $\begin{array}{l}\text { Pre-operative IOP } \\
(\mathbf{m m H g})\end{array}$ \\
\hline POAG & 8 & 35.7 \\
\hline NVG & 7 & 36.7 \\
\hline IG & 3 & 28 \\
\hline CG & 2 & 37 \\
\hline IOHT SOT & 1 & 26 \\
\hline MG & 1 & 50 \\
\hline
\end{tabular}

POAG: Primary open-angle glaucoma; NVG: Neovascular glaucoma; IG: Inflammatory glaucoma; CG: Congenital glaucoma; IOHT SOT: Intraocular hypertension with silicone oil retinal tamponade; MG: Malignant glaucoma

Table 4: Mean pre-operative pain.

\begin{tabular}{|l|l|}
\hline & Pre-op \\
\hline Pain & $16(72.7 \%)$ \\
\hline No pain & $6(27.3 \%)$ \\
\hline Mean numeric scale score & 3.1 \\
\hline
\end{tabular}

Visual acuity before treatment: Visual acuity ranged from light perception to $7 / 10$ (Parinaud scale). For 17 patients $(77.27 \%$ ) it was less than $1 / 10$; only 5 patients $(22.72 \%)$ had superior vision. Table 6 summarises the visual acuity values.

\section{Post-operative results}

Post-operative intraocular pressure (Figure 2): We noted a decrease in mean intraocular pressure of $44.8 \%$ on $\mathrm{D} 7,30.40 \%$ at $\mathrm{M} 1$ and $29.30 \%$ at 1 year, with a statistically significant difference at 1 week $(p=0.001)$ and 1 year $(p=0.008)$. The data are shown in the Table 7 .

Table 5: Summary of baseline treatments and therapeutic scores.

\begin{tabular}{|l|l|l|}
\hline Treatments & Number & $\begin{array}{l}\text { Pre-operative } \\
\text { cumulative score }\end{array}$ \\
\hline Monotherapy & $1(4.5 \%)$ & 1 \\
\hline Dual therapy & $2(9.1 \%)$ & 4 \\
\hline Triple therapy & $8(36.4 \%)$ & 16 \\
\hline Quadruple therapy & $11(50 \%)$ & 22 \\
\hline Diamox & $7(27.8 \%)$ & 7 \\
\hline Total therapeutic score & & 2.2 \\
\hline
\end{tabular}

Table 6: Pre- and post-operative visual acuity, by number of patients.

\begin{tabular}{|l|l|l|l|}
\hline Initial VA & $\mathbf{n}$ & VA at 1 year & $\mathbf{n}$ \\
\hline LP- & $3(13.6 \%)$ & LP- & $3(13.6 \%)$ \\
\hline LP+ & $9(40.9 \%)$ & LP+ & $9(40.9 \%)$ \\
\hline HM & $3(13.6 \%)$ & HM & $3(13.6 \%)$ \\
\hline CF1 & $2(9.1 \%)$ & CF1 & $2(9.1 \%)$ \\
\hline $1-/ 10$ & $1(4.5 \%)$ & $1-/ 10$ & $1(4.5 \%)$ \\
\hline $1.5 / 10$ & $1(4.5 \%)$ & $1 / 20$ & $1(4.5 \%)$ \\
\hline $2-/ 10$ & $1(4.5 \%)$ & $2-/ 10$ & $1(4.5 \%)$ \\
\hline $4-/ 10$ & $1(4.5 \%)$ & $2.5 / 10$ & $1(4.5 \%)$ \\
\hline $7-/ 10$ & $1(4.5 \%)$ & $7-/ 10$ & $1(4.5 \%)$ \\
\hline
\end{tabular}

LP: Light perception; HM: Hand motion; CF1: Counting fingers at 1 meter.

Table 7: Summary table of intraocular pressure data.

\begin{tabular}{|l|l|l|l|l|l|}
\hline & D0 & D7 & M1 & 1Y & P \\
\hline Number & 22 & 22 & 22 & 22 & 26.4 \\
\hline Mean IOP & 35.7 & 21.2 & 27.2 & 12.2 & 0.05 \\
\hline Standard deviation & 8.9 & 8 & 12.3 & 60 & 10 \\
\hline Max. IOP & 58 & 42 & 50 & 7 & $29.30 \%$ \\
\hline Min. IOP & 22 & 8 & $30.40 \%$ & $7(31.8 \%)$ \\
\hline Reduction in IOP (\%) & & $44.80 \%$ & $5 / 15(33.3 \%)$ & 12.2 \\
\hline IOP $<21$ & 0 & $11(50 \%)$ & 12.3 & 2.93 & 0.006 \\
\hline SD & 8.9 & 8 & 2.34 & 0.008 \\
\hline t-value & & 6.15 & 0.035 & \\
\hline p-value & & 0.001 & & \\
\hline
\end{tabular}


Post-operative pain: We saw an improvement in pain in 15 out of the 16 eyes that were reported to be painful at the outset. Nine eyes were no longer painful at all and 6 others were less painful. Of the 7 that remained painful, 4 had neovascular glaucoma with significant ocular hypertension initially, one of which presented an increase in post-operative hypertension at 1 year. The last patient with constant pain had malignant glaucoma with increased ocular hypertension: The treatment failed (Table 8).

Biomicroscopic examination: Assessment of surface pathology by Oxford score showed stability for most patients, with a mean score that fell from 1.3 to 1 . Three eyes saw an improvement in the condition of the ocular surface. These were two neovascular glaucoma cases and one eye with silicone oil retinal tamponade following retinal detachment.

Change in local treatment during the post-operative period: The mean number of pressure-lowering medical treatments was 2.2 pre-operatively compared to 1.7 post-operatively at one year. For patients who were on local and general treatment, the normalisation of their IOP enabled them to stop or reduce oral acetazolamide. One patient with primary open-angle glaucoma with no

Table 8: One-year post-operative results for pain.

\begin{tabular}{|l|l|l|}
\hline & Pre-operative & 1 year post-operative \\
\hline In pain & $16(72.7 \%)$ & $7(31.8 \%)$ \\
\hline No pain & $6(27.3 \%)$ & $15(68.2 \%)$ \\
\hline NS & 3.1 & 0.7 \\
\hline
\end{tabular}

history of filtering surgery was no longer taking any local or general medical treatment. There was a significant difference $(p=0.006)$ in the reduction in medical treatment at 1 year $(p<0.05$, paired Student's t-test) (Table 9).

Post-operative visual acuity: All patients had unchanged visual acuity post-operatively except two. One pseudophakic eye with congenital glaucoma saw its visual acuity halve, from $4 / 10$ to $2.5 / 10$. The other pseudophakic eye with primary open-angle glaucoma saw its acuity drop from $1.5 / 10$ to $1 / 20$. No retinal aetiology was found to explain this decrease in visual acuity in these two patients. Of the other eyes with visual acuity greater than or equal to $1 / 10$, they maintained useful visual acuity (Table 6).

Summary: The various data on pain, intraocular pressure and post-operative therapeutic score at one year are shown in Table 10.

\section{Detailed Results for Each Group \\ Primary open-angle glaucoma (POAG) $(n=8)$}

The initial mean IOP was $34.8 \pm 7.6 \mathrm{mmHg}$, dropping to $20.1 \pm 8.9 \mathrm{mmHg}$ at 1 year (Figure 3). The decrease in IOP at 1 year was $42.2 \%(p=0.009)$. The mean pain scale score fell from 3.2 to 0 at 1 year post-operatively.

Clinical examination including inflammation and $\mathrm{Ox}$ ford grading remained unchanged at 1 year, with an average Oxford score of 0.75 .

The therapeutic score fell from 2.25 to 2.1 at 1 year post-operatively.

Table 9: Change in therapeutic score at one year post-operatively.

\begin{tabular}{|l|l|l|l|}
\hline & Pre-operative & $\mathbf{1}$ year post-operative & p-value \\
\hline Therapeutic score & 2.2 & 1.7 & 0.017 \\
\hline
\end{tabular}

Table 10: Summary data.

\begin{tabular}{|l|l|l|l|l|l|}
\hline IOP $(\mathbf{m m H g})$ & Pain & \multicolumn{3}{l|}{ Therapeutic score } \\
\hline Before & After & Before & After & Before & After \\
\hline $37.5 \pm 8.6$ & $26.5 \pm 12.5$ & $16(72.7 \%)$ & $7(31.8 \%)$ & 2.2 & 1.7 \\
\hline
\end{tabular}

\section{IOP in POAG group}



10

0

J0

$\mathrm{J} 7$

M1

$1 \mathrm{~A}$

Figure 3: Change in IOP in the primary open-angle glaucoma group (POAG). 


\section{IOP in NVG group}

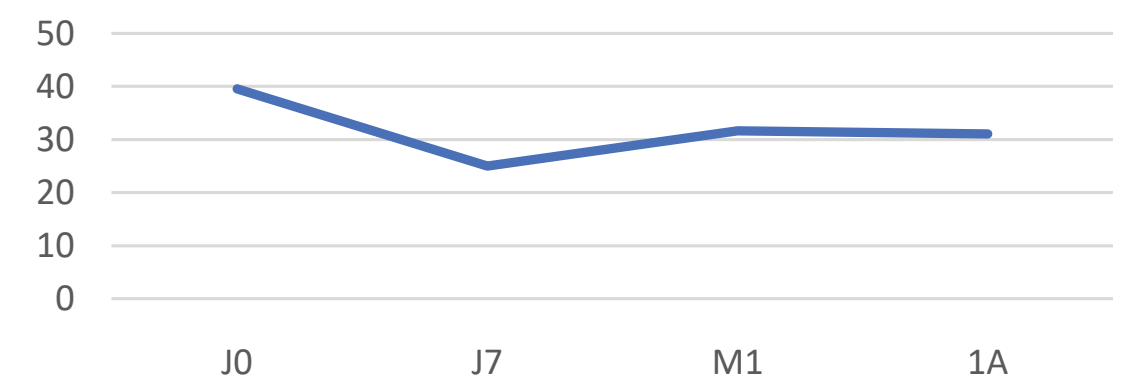

Figure 4: Change in IOP in the neovascular glaucoma (NVG) group.

\section{IOP in IG group}



Figure 5: Change in IOP in the inflammatory glaucoma (IG) group.

Two patients had a useful visual acuity of greater than or equal to $1 / 10$ pre-operatively compared to a single patient post-operatively.

\section{Neovascular glaucoma (NVG) $(n=7)$}

In this group, the initial IOP was $39.6 \pm 10.2 \mathrm{mmHg}$, falling to $31.1 \pm 17.1 \mathrm{mmHg}$ at 1 year, resulting in an average pressure drop of $36.9 \%(p<0.05)$ (Figure 4$)$. Pain fell from a mean numeric scale score of 5.4 to 1.4 one year post-operatively.

Clinical examination remained stable, with the Oxford score dropping from 1.8 at baseline to 1.5 one year after treatment.

The therapeutic score fell from 2.28 initially to 1.8 one year after treatment.

Only one patient had useful visual acuity (measured at $2 / 10$ ) that remained the same post-operatively.

\section{Ocular hypertension with inflammatory glaucoma (IG) ( $n=3)$}

The mean IOP value in this group fell from $28 \pm$ $7.2 \mathrm{mmHg}$ to $21 \pm 1.4 \mathrm{mmHg}$ at 1 year, which represents a mean reduction of $25 \%$, but this difference was not statistically significant $(p=0.157)$ (Figure 5$)$. The mean numeric pain scale score fell from 1.3 to 0.3 .
Clinical examination revealed surface pathology with an unchanged Oxford score of 2 pre- and post-operatively at one year.

The therapeutic score dropped from 2.3 to 1.3 one year after laser treatment.

None of the treated eyes had any useful visual acuity.

\section{Congenital glaucoma (CG) $(n=2)$}

In this group, the initial mean IOP was $37 \pm 7 \mathrm{mmHg}$ and fell to $25.5 \pm 0.7 \mathrm{mmHg}$ at 1 year, which represents an average decrease in IOP of $31.1 \%$, but this difference was not statistically significant $(p=0.237)$ (Figure 6). The mean numeric pain scale score fell from 3.5 to 0 one year after laser treatment.

The clinical examination showed no inflammatory signs before or after treatment.

The therapeutic score remained unchanged at 2 .

One eye had a pre-operative visual acuity of $4 / 10$, which decreased to $2.5 / 10$ post-operatively.

Ocular hypertension with retinal detachment and silicone oil tamponade (IOHT SOT) $(n=1)$

The initial IOP was $26 \mathrm{mmHg}$ and increased to 


\section{IOP in CG group}

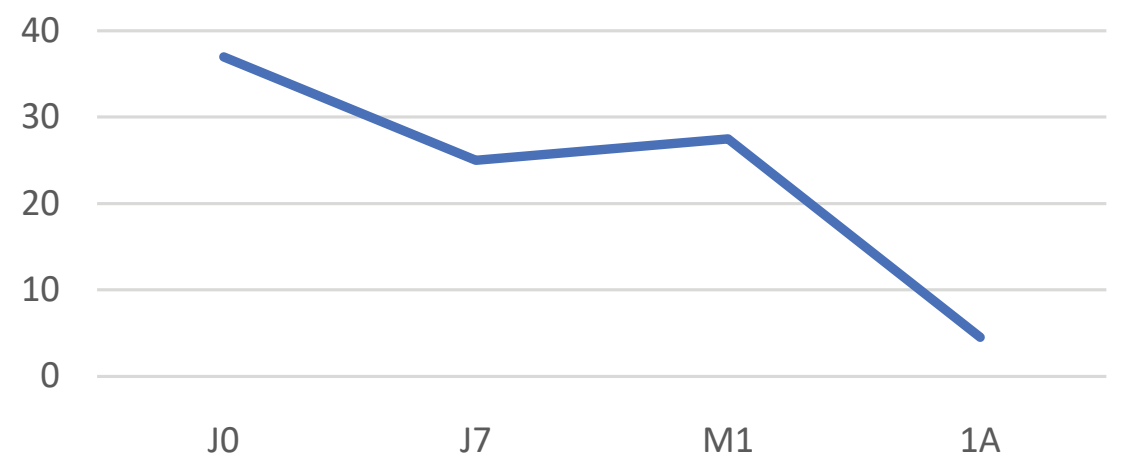

Figure 6: Change in IOP in the congenital glaucoma (CG) group.

\section{IOP in the IOHT SOT group}



Jo

$\mathrm{J} 7$

M1

$1 \mathrm{~A}$

Figure 7: Change in IOP in the IOHT with internal silicone oil tamponade group (IOHT SOT).

$34 \mathrm{mmHg}$ at 1 year, resulting in an increase in IOP of $30.7 \%$ (Figure 7 ). It should be noted that the silicone oil was still in the eye and was removed remotely. The numeric pain scale score fell from 5 to 3 one year after treatment.

The therapeutic score remained unchanged at 3.

Biomicroscopic examination found significant local inflammation, as at baseline, with a very slight improvement in surface pathology, evidenced by the Oxford score dropping from 4 to 3 . This patient, for whom treatment failed, later underwent a conventional thermal diode laser treatment.

\section{Malignant glaucoma (MG) $(n=1)$}

The mean IOP value was $29 \mathrm{mmHg}$ pre-operatively and increased to $50 \mathrm{mmHg}$ at 1 year post-operatively, resulting in an average IOP increase of $72.4 \%$ (Figure 8 ).

Biomicroscopic examination was unchanged with no inflammatory signs and an Oxford score of 0 .

The therapeutic score remained stable at 2 .

This was therefore the second patient for whom treatment failed.
Changes in IOP by aetiology are summarised in Table 11.

\section{Discussion}

In our study, the use of subliminal cyclodiode with a $31.3 \%$ duty cycle demonstrated a statistically significant efficacy in terms of a reduction in both intraocular pressure and pain after one year.

Laser destruction of the ciliary bodies is a technique designed to reduce aqueous humour production and therefore intraocular pressure and pain in highly painful and advanced glaucoma. Up until ten years ago, the only available procedure was thermal cyclodestruction of the ciliary bodies using an Nd: YAG $1064 \mathrm{~nm}$ laser $[4,5]$. This treatment generated numerous inflammatory complications and the outcome was unpredictable in the long term, sometimes even resulting in phthisis bulbi [4-6]. A new technique has appeared in recent years with the introduction of the diode laser $(810 \mathrm{~nm})$, followed by the SubCyclo [7] micropulsed diode laser, which has improved results by reducing complications. This laser can target the pigmented cells of the ciliary epithelium, because absorption by melanin in pigment- 
Table 11: Summary of change in IOP in each group.

\begin{tabular}{|l|l|l|l|l|}
\hline & D0 & D7 & M1 & 1Y \\
\hline POAG & 34.8 & 18.6 & 18 & 20.1 \\
\hline NVG & 42.5 & 19 & 20 & 26.8 \\
\hline IG & 28 & 18 & ND & 21 \\
\hline CG & 37 & 25 & 27.5 & 25.5 \\
\hline IOHT SOT & 26 & 8 & ND & 34 \\
\hline MG & 29 & 23 & 50 & 50 \\
\hline
\end{tabular}

POAG: Primary open-angle glaucoma; NVG: Neovascular glaucoma; IG: Inflammatory glaucoma; CG: Congenital glaucoma; IOHT SOT: IOHT caused by retinal detachment, with internal silicone oil tamponade; MG: Malignant glaucoma.

\section{IOP in MG group}

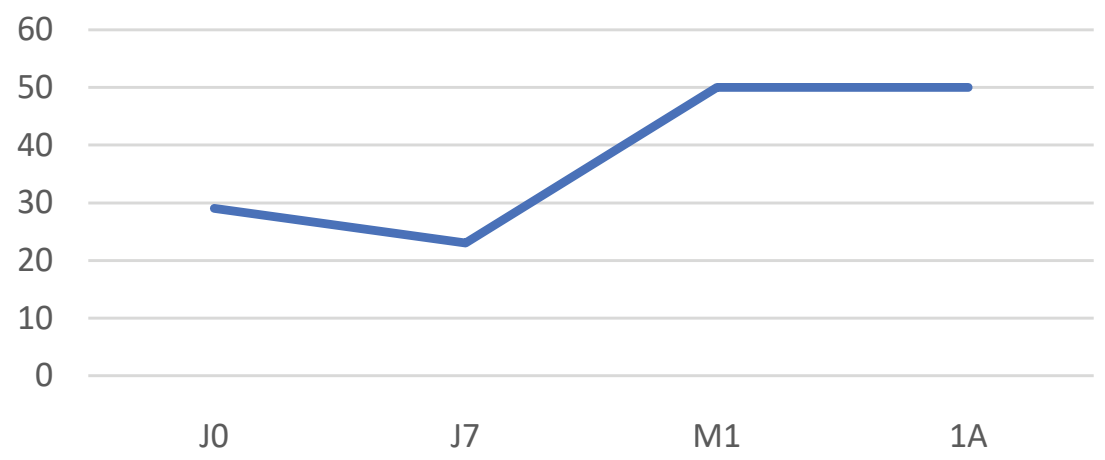

Figure 8: Change in IOP in the malignant glaucoma group (MG).

ed cells is three times greater at $810 \mathrm{~nm}$, meaning this mode of operation results in improved efficacy with less inflammation. Energy is delivered in two cycles: The ON cycle, which causes photocoagulation, followed by the OFF cycle, which allows cooling of adjacent tissues by remaining below the photocoagulation threshold. There is therefore a marked decrease in long-term complications with a more predictable effect in terms of IOP reduction $[8,9]$. It has also been shown that the microanatomy of the ciliary processes is respected following the use of this laser, thanks to the cyclic mode of energy delivery. This mode minimises the harmful effects on the surrounding tissue by avoiding the disruption of the ciliary body, epithelium and ciliary processes observed under histological examination after using the transscleral laser [10].

The subthreshold laser was first used in the field of medical retina and several studies have been published on this use [11-17]. Pollack, et al. [15] conducted a preclinical study to refine the parameters and define the subliminal threshold. Parodi, et al. [12] found that the subthreshold laser was more effective than the krypton laser in the treatment of macular oedema. Li, et al. [17] observed that the micropulsed diode laser induces a reduction in inflammatory mediators in the retinal pigment epithelium, which slows down the cell stress and tissue heating responsible for protein denaturation. Laursen, et al. [13] demonstrated stabilisation or even improvement in clinically significant diabetic macular oedema and a lower rate of complications. Moorman, et al. [14] demonstrated that the subthreshold laser is delivered specifically to the pigment epithelium in the treatment of ischaemic macular oedema and diabetic retinopathy and leads to fewer complications.

These results encouraged the use of the subthreshold laser in glaucoma. A decrease in IOP of between 30 and $40 \%$ was observed at 1 year, according to the literature [18-21]. Better tolerance than the continuous mode diode laser is noted, including significantly less inflammation and rare adjacent tissue damage (scleral thinning, conjunctival burning).

The objective of our study was to evaluate the efficacy, safety and side effects of this treatment after one year in a population with refractory and/or painful glaucoma. We saw a reduction in overall IOP at 1 year of $29.3 \%$. IOP reduction is seen as early as the first week and this could be explained by an increase in aqueous humour outflow via the uveoscleral route. This has already been observed in in vitro studies of transscleral cycloablation, such as the study by Schubert, which observed this phenomenon in pig and human eyes [22], and the study by Liu, et al. [23], which observed histological changes that indirectly explain the increase in uveoscleral outflow. A recent literature review confirmed the drop in intraocular pressure with decreased aqueous humour production and better uveoscleral 
drainage. An effect was also noted on the longitudinal fibres of the ciliary muscle, causing the scleral spur to move as a result of the improved trabecular drainage [24]. At 1 year in our study, 7 eyes (31.8\%) had an IOP of less than $21 \mathrm{mmHg}$. Among the 15 eyes that retained an IOP of over $21 \mathrm{mmHg}$ at 1 year, a reduction of at least $30 \%$ in the initial IOP was observed in 6 eyes (40\%).

We also saw a sizeable and significant reduction in post-operative pain. As the maximum effect of the ciliary body subliminal cyclodiode can be assessed four weeks after treatment, we did not retreat any patient prior to this point. Only two patients remained in pain and required a second treatment at 16 weeks. The first eye was a case of neovascular glaucoma following central retinal vein occlusion associated with severe pain (NS 5), which fell to NS 2 after the second laser treatment. The other patient was monitored for inflammatory glaucoma and pain estimated at NS 4, which stabilised to NS 0 , leaving the patient pain-free. Although the pain was less after retreatment, we can assume that there were local inflammatory factors generating persistent pain, along with an associated surface pathology in both cases. Our retreatment rate (1\%) was significantly lower than in the literature, with retreatment rates ranging from $6 \%$ to $33 \%$ in the most recent studies $[8,9,20,25$ 27]. However, our population was small and we did not indicate a second treatment if the patient was no longer in pain. In the study by Bloom, et al. [28], $70 \%$ of patients were retreated, with two-thirds of these retreatments occurring in the first 3 months post-operatively. It should be noted that the retreatments did not lead to complications, but the lack of clinical data and sufficient follow-up mean that no definitive conclusions can be drawn.

We had two treatment failures. These were a case of hypertension with silicone oil tamponade and a malignant glaucoma case. In the first case, silicone oil was still present in the eye at the time of clinical observation, while the malignant glaucoma did not respond to any treatment. The pressure-lowering trend appeared to be greater in the POAG subgroup and then in the neovascular glaucoma subgroup, followed by the inflammatory glaucoma and congenital glaucoma subgroups. However, the small number of subjects in each subgroup means that no definitive conclusions can be drawn. The literature review shows that the majority of cases of treatment failure involve congenital glaucoma, which is considered difficult to treat. In the Chinese study by Cheung, et al. [29], the success rate was estimated to be $67.3 \%$, with a higher failure rate in the phacomorphic glaucoma and angle-recession glaucoma groups. In light of these failures, consideration could be given to changing the treatment parameters. We used $2 \mathrm{~W}$ of power and an exposure time of 80 seconds per semi-circumference with a duty cycle of $31.3 \%$. Studies have shown that the power level used impacts the drop in pressure and therefore the reduction in pain. The identified critical threshold (efficacy/safety) appears to be 112 to $115 \mathrm{~J}$ - or 90 seconds per hemisphere with $2 \mathrm{~W}$ and $31.3 \%$ - for the upper threshold value, because above $200 \mathrm{~J}$ the reduction in IOP would increase but would also be associated with more significant complications (inflammatory complications or total destruction leading to phthisis bulbi) $[24,30]$.

In terms of complications, the onset of macular oedema has been described with the transscleral laser, whereas multiple studies have demonstrated the safety of the micropulsed laser due to the absence of any thermal effect when treating macular disease (central serous chorioretinopathy, diabetic oedema, oedema secondary to venous occlusions). Some authors reported transient loss of vision during the first months of treatment [24]. In our study, we found deterioration of visual acuity in just two cases (1 POAG and 1 CG). While the majority of our patients had reduced vision at baseline, this vision did not deteriorate. We found no clear explanation - retinal or otherwise - for the loss of vision in our two patients. It could be useful to conduct a prospective study with OCT (optical coherence tomography) before and after subthreshold laser treatment [28], but this was not possible for us due to the retrospective nature of this study.

With regard to medical treatment, we also noted a reduction in the average number of treatments, from 2.2 to 1.7 at 1 year. Although the definition of treatment success does not take into account the post-operative use of local and general treatments, reducing pressure-lowering eye drops has a significant impact on maintaining patient quality of life. For all cases, the therapeutic score decreased by $25.1 \%$, consistent with the results of other studies, in which reduction rates range from 20 to $53 \%[8,9,18,20,25,26,31]$.

\section{Conclusion}

Our study shows a reduction in IOP and pain at one year in refractory glaucoma patients treated with subthreshold transscleral cyclophotocoagulation (SubCyclo) with a $31.3 \%$ duty cycle, 80 s per hemisphere and $2 \mathrm{~W}$ of power. Despite the retrospective observational nature of the study and the small population size, we believe that this technique is useful in the management of refractory glaucoma.

Given that this technique results in far fewer complications than conventional transscleral diode laser, consideration could be given to extending the indication to include patients with refractory glaucoma and a relatively good level of visual acuity. Comparative and prospective studies with standardised success criteria and long follow-up periods, would enable the ideal parameters to be determined prior to any such extension of indication. 
The ciliary body location varying between patients and even among quadrants of a same eye, it would be interesting to evaluate the impact of the probe positioning and speed of movement on clinical outcomes.

Ciliary body transillumination on patients prior to cyclodiode laser treatment should probably be considered in order to ensure optimal probe placement and motion velocity during the treatment.

\section{References}

1. Tham YC, Li X, Wong TY, Quigley HA, Aung T, et al. (2014) Global prevalence of glaucoma and projections of glaucoma burden through 2040: A systematic review and meta-analysis. Ophthalmology 121: 2081-2090.

2. Heijl A, Leske MC, Bengtsson B, Hyman L, Bengtsson B, et al. (2002) Reduction of intraocular pressure and glaucoma progression: Results from the Early Manifest Glaucoma Trial. Arch Ophthalmol 120: 1268-1279.

3. Pastor SA, Singh K, Lee DA, Juzych MS, Lin SC, et al. (2001) Cyclophotocoagulation: A report by the American Academy of Ophthalmology. Ophthalmology 108: 21302138.

4. Hampton C, Shields MB, Miller KN, Blasini M (1990) Evaluation of a protocol for transscleral neodymium: YAG cyclophotocoagulation in one hundred patients. Ophthalmology 97: 910-917.

5. Klapper RM, Wandel T, Donnenfeld E, Perry HD (1988) Transscleral neodymium:YAG thermal cyclophotocoagulation in refractory glaucoma. A preliminary report. Ophthalmology 95: 719-722.

6. Simmons RB, Shields MB, Blasini M, Wilkerson M, Stern RA (1991) Transscleral Nd:YAG laser cyclophotocoagulation with a contact lens. Am J Ophthalmol 112: 671-677.

7. Gupta N, Weinreb RN (1997) Diode laser transscleral cyclophotocoagulation. J Glaucoma 6: 426-429.

8. Aquino MCD, Barton K, Tan AMWT, Sng C, Li X, et al. (2015) Micropulse versus continuous wave transscleral diode cyclophotocoagulation in refractory glaucoma: a randomized exploratory study. Clin Exp Ophthalmol 43: 40-46.

9. Emanuel ME, Grover DS, Fellman RL, Godfrey DG, Smith O, et al. (2017) Micropulse Cyclophotocoagulation: Initial Results in Refractory Glaucoma. J Glaucoma 26: 726-729.

10. Pantcheva MB, Kahook MY, Schuman JS, Rubin MW, Noecker RJ (2007) Comparison of acute structural and histopathological changes of the porcine ciliary processes after endoscopic cyclophotocoagulation and transscleral cyclophotocoagulation. Clin Exp Ophthalmol 35: 270-274.

11. Sivaprasad S, Sandhu R, Tandon A, Sayed-Ahmed K, McHugh DA (2007) Subthreshold micropulse diode laser photocoagulation for clinically significant diabetic macular oedema: A three-year follow up. Clin Exp Ophthalmol 35: 640-644.

12. Parodi MB, Spasse $S$, lacono $P$, Di Stefano G, Canziani T, et al. (2006) Subthreshold grid laser treatment of macular edema secondary to branch retinal vein occlusion with micropulse infrared (810 nanometer) diode laser. Ophthalmology 113: 2237-2242.

13. Laursen ML, Moeller F, Sander B, Sjoelie AK (2004) Subthreshold micropulse diode laser treatment in diabetic macular oedema. Br J Ophthalmol 88: 1173-1179.

14. Moorman CM, Hamilton AM (1999) Clinical applications of the MicroPulse diode laser. Eye (Lond) 13: 145-150.

15. Pollack JS, Kim JE, Pulido JS, Burke JM (1998) Tissue ef- fects of subclinical diode laser treatment of the retina. Arch Ophthalmol 116: 1633-1639.

16. Berger JW (1997) Thermal modelling of micropulsed diode laser retinal photocoagulation. Lasers Surg Med 20: 409415.

17. Li Z, Song Y, Chen X, Chen Z, Ding Q (2015) Biological Modulation of Mouse RPE Cells in Response to Subthreshold Diode Micropulse Laser Treatment. Cell Biochem Biophys 73: $545-552$.

18. Tan AM, Chockalingam M, Aquino MC, Lim ZI-L, See JL-S, et al. (2010) Micropulse transscleral diode laser cyclophotocoagulation in the treatment of refractory glaucoma. Clin Experiment Ophthalmol 38: 266-272.

19. Chen MF, Kim CH, Coleman AL (2019) Cyclodestructive procedures for refractory glaucoma. Cochrane Database Syst Rev 3: CD012223.

20. Kuchar S, Moster MR, Reamer CB, Waisbourd M (2016) Treatment outcomes of micropulse transscleral cyclophotocoagulation in advanced glaucoma. Lasers Med Sci 31: 393-396.

21. Benhatchi N, Bensmail D, Lachkar Y (2019) Benefits of SubCyclo Laser Therapy Guided by High-frequency Ultrasound Biomicroscopy in Patients With Refractory Glaucoma. J Glaucoma 28: 535-539.

22. Schubert HD, Agarwala A, Arbizo V (1990) Changes in aqueous outflow after in vitro neodymium: yttrium aluminum garnet laser cyclophotocoagulation. Invest Ophthalmol Vis Sci 31: 1834-1838.

23. Liu GJ, Mizukawa A, Okisaka S (1994) Mechanism of intraocular pressure decrease after contact transscleral continuous-wave Nd:YAG laser cyclophotocoagulation. Ophthalmic Res 26: 65-79.

24. Sanchez FG, Peirano-Bonomi JC, Grippo TM (2018) Micropulse Transscleral Cyclophotocoagulation: A Hypothesis for the Ideal Parameters. Med Hypothesis Discov Innov Ophthalmol 7: 94-100.

25. Lee JH, Shi Y, Amoozgar B, Aderman C, De Alba Campomanes A, et al. (2017) Outcome of Micropulse Laser Transscleral Cyclophotocoagulation on Pediatric Versus Adult Glaucoma Patients. J Glaucoma 26: 936-939.

26. Williams AL, Moster MR, Rahmatnejad K, Resende AF, Horan T, et al. (2018) Clinical Efficacy and Safety Profile of Micropulse Transscleral Cyclophotocoagulation in Refractory Glaucoma. J Glaucoma 27: 445-449.

27. Jammal AA, Costa DC, Vasconcellos JPC, Costa VP (2019) Prospective evaluation of micropulse transscleral diode cyclophotocoagulation in refractory glaucoma: 1 year results. Arq Bras Oftalmol 82: 381-388.

28. Bloom PA, Tsai JC, Sharma K, Miller MH, Rice NS, et al. (1997) « Cyclodiode ». Trans-scleral diode laser cyclophotocoagulation in the treatment of advanced refractory glaucoma. Ophthalmology 104: 1508-1519; discussion 15191520.

29. Cheung JJC, Li KKW, Tang SWK (2019) Retrospective review on the outcome and safety of transscleral diode laser cyclophotocoagulation in refractory glaucoma in Chinese patients. Int Ophthalmol 39: 41-46.

30. Keilani C, Benhatchi N, Bensmail D, Abitbol O, Amara A, et al. (2020) Comparative Effectiveness and Tolerance of Subliminal Subthreshold Transscleral Cyclophotocoagulation With a Duty Factor of $25 \%$ Versus $31.3 \%$ for Advanced Glaucoma. J Glaucoma 29: 97-103.

31. Gavris MM, Olteanu I, Kantor E, Mateescu R, Belicioiu R (2017) IRIDEX MicroPulse P3: Innovative cyclophotocoagulation. Rom J Ophthalmol 61: 107-111. 